\title{
Towards the safer use of medicines
}

\author{
A W Asscher, G D Parr, V B Whitmarsh
}

In Britain the tools are now available to provide better information on safety of medicines in both hospital and community settings, and this could be done at relatively modest cost. The needs of patients, doctors, and pharmacists are changing; although more research is needed, such information as is presently available must be both better and more widely publicised and understood. Universities, government, the pharmaceutical industry, and educated journalism all have an important part to play in this process.

Some 2500 drugs are listed in the British National Formulary, and biotechnology will soon provide even more. An aging population with multiple illnesses will increasingly challenge therapeutic skills (figure). ${ }^{12}$

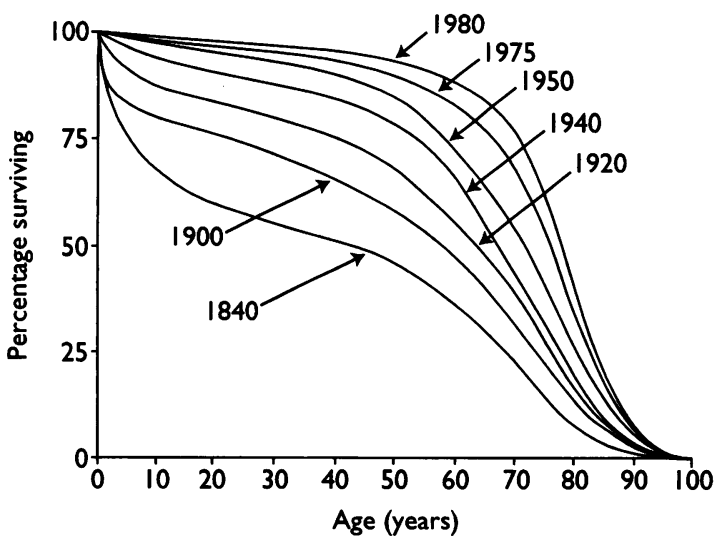

Survival curve. Adapted from Coni et al's ${ }^{\text {; }}$ reproduced with permission of Blackwell Science

Patients are asking for more information, which comes from various sources. Both doctors and patients are likely to be confused, and this will have a detrimental effect on the use of medicines. No human activity is risk free-cycling, driving, or even crossing the road carry surprisingly high risks. ${ }^{3}$ Taking modern medicines is a relatively safe activity, ${ }^{4}$ but because risks can never be wholly eliminated, vigilance and continuous re-evaluation are required.

\section{Definitions and size of the problem}

Adverse drug reactions are unwanted or unintended effects of a medicine which occur during its proper use. Adverse events are untoward occurrences following exposure to a medicine but not necessarily caused by the medicine. Most doctors understand risk to be the probability of a particular adverse outcome following exposure to a given amount of hazard. Other disciplines-and indeed patients-often use different definitions, and this may be a source of confusion in discussions between doctors and their patients.

When a product licence is granted, little is known about the safety of the new drug; on average only about 1500 patients have been exposed to it. ${ }^{5}$ Therefore throughout the life cycle of a modern medicine there is a continuous process of risk identification, assessment, and management. Risk can be measured but safety is always judged.

In the 1960s the incidence of adverse drug reactions in hospitals ranged from $10 \%$ to $18 \% \%^{67}$; Jick et al reported an incidence of $0.09 \%$ fatal adverse drug reactions in hospital inpatients. ${ }^{89}$ More recently the Harvard medical practice study showed that in 30195 inpatient admissions to acute non-psychiatric hospitals, $0 \cdot 7 \%$ of patients reacted adversely to drugs. ${ }^{10}$

In the community the incidence of adverse drug reactions ranges from $2 \cdot 6 \%$ to $41 \% .^{891112}$ These wide variations are due to differences in definition, methodology, and clinical setting. From $4 \%$ to $12 \%$ hospital admissions are related to adverse drug reactions, ${ }^{1314}$ But such figures reveal little about the incidence of adverse drug reactions in the community because drug exposure in the population is not known. Most of the British data on incidence of adverse drug reactions is old and needs to be updated. The "yellow card" scheme, ${ }^{15}$ which acts as a signal generator for regulators, can be used to relate the reported number of adverse reactions to drug sales and thus for calculating crude overall estimates. Confirmation and refinement are required, however, and with record linkage the British health care system has a unique opportunity to improve information on medicines.

\section{Strategies for reducing risk}

Adverse drug reactions may be caused by errors in manufacturing, supplying, prescribing, giving, or taking medicines-these are the so called extrinsic adverse drug reactions. Alternatively, inherent properties of the medicine itself may cause unwanted effects; these are known as intrinsic adverse drug reactions. Until we know much more about the mechanisms of intrinsic reactions, their impact can be limited by legislative measures and by ensuring as far as possible that minimum effective doses are prescribed.

Extrinsic adverse drug reactions are more easily averted. Errors in manufacturing, labelling, ampouling, and dispensing are fortunately rare. The major cause of extrinsic reactions is errors by doctors. Abramson et al found that 98 of 145 untoward episodes identified on an intensive care unit were due to human error. ${ }^{16}$ Eighteen per cent of drugs related to adverse reactions in the Harvard medical practice study were judged to be due to negligence, defined as failure to meet the standard of care reasonably expected of a physician qualified to take care of the patient in question. ${ }^{10}$ In a British study of coroners' cases, medication errors accounted for $22 \%$ of all deaths due to adverse drug reactions. ${ }^{17}$ Extrinsic reactions could be reduced by improving doctors' prescribing practice.

\section{Role of the patient in safer use of medicines}

An increasing proportion of patients and their carers wish to be partners in decisions about medication..$^{18}$ Patients need information on benefit and risks of treatment so that they can make informed decisions. At any one time $46 \%$ of the British population is taking medicines, and of these $62 \%$ wish to have information leaflets (box 1). ${ }^{19-21}$ In January 1994, patient information leaflets for new medicines became compulsory under a European Commission directive (92/27). 


\section{Box 1-Information concerning} medicines required by the patient ${ }^{19}$

- When and how to take the medicine

- Unwanted effects and what to do about them

- Precautions (such as possible effects on driving)

- Problems with alcohol or drugs

- The name of the medicine

- The purpose of the treatment

- What to do if a dose is missed

Patients' information needs are shown in box 1; the directive obliges manufacturers to provide much more information, and this may prove confusing (box 2).

Demand for information about medicines goes beyond the provision of patient information leaflets. The public needs to be educated about the risks and benefits of medical interventions. The responsibility for such education should start in the schools. ${ }^{22}$ It seems unlikely that British schools will be eager to take on these extra responsibilities, even though modern video and computer education methods could introduce children to the notion of risk and benefits.

\section{Patients' perception of risks of medicines}

Studies designed to measure perceived risk $^{23}$ indicate that the degree of personal control the risk taker has over the risk is of special importance because patients do perceive their doctor as putting them at risk. In Sweden, 961 people were interviewed about their attitudes to prescription drugs. ${ }^{23}$ They thought that unwanted effects were mainly caused by sensitivity to particular drugs, improper prescribing, and incorrect diagnosis and also that improper monitoring by the doctor and failure to give patients adequate information were important causes of adverse drug reactions.

In an investigation of the attitudes of 1034 British patients suffering from ankylosing spondylitis, $47 \%$ reported serious adverse drug reactions associated with their medication. ${ }^{24}$ They regarded insufficient information and inadequate monitoring by the doctor as important causes of adverse drug reactions. To a lesser degree they felt that drugs were insufficiently tested and inadequately regulated.

In various studies patients have been asked what gamble they would be prepared to take to change their present state to a future state that could be better but might be worse. This technique, known as the standard gamble, has shown that some patients are prepared to take more risk than their doctors offer them. Patients with severe rheumatoid arthritis were prepared to risk using a drug that carried an $80 \%$ chance of death if the medicine being offered produced a complete cure to survivors. ${ }^{25}$ There is difficulty in interpreting the views of patients, for the high risk acceptance of patients with rheumatoid disease was not borne out by patients with ankylosing spondylitisasked what should happen if a drug used to treat their disease was found to cause fatalities, $61 \%$ said it should be banned. ${ }^{26}$ However, the risk of blood dyscrasias from phenylbutazone ( 1 in 50000$)^{27}$ has been accepted by rheumatologists and regulators as acceptable for patients with ankylosing spondylitis. Do the patients suffering from ankylosing spondylitis who seem so risk averse know the risks inherent in taking this drug? Answers to questions such as this depend on how the question is framed and, given the contradiction referred to above, a uniform approach to discovering patients' views is needed.
It is not possible to generalise about the degree of risk an individual patient is prepared to take, but appropriate research can elucidate the views of groups of patients and form a basis for discussions with individuals. Even with the most rational central decisions, some people will consider that they are at undue risk. ${ }^{3}$ Nevertheless, all involved in helping to inform patients about medicines should be aware of patients' perceptions if the communication process is to be effective.

\section{Role of doctors in the safer use of medicines}

Recently the doctor's task has become harder. Calls on practitioners' time have mounted, as have patients' expectations. The average length of a consultation with a general practitioner, 8-10 minutes ${ }^{28}$ leaves little time for discussion of benefits and risks of medicines once doctor and patient have decided that drug treatment is required. Prescribing decisions leave some general practitioners uneasy, ${ }^{29}$ chiefly because of the complexity of assessing risks versus benefits in individual patients but also because therapeutic knowledge rapidly becomes outdated. Even for experts in therapeutics there is no simple way of deciding how much information to give a patient. Drury ${ }^{30}$ considered that explanation of the risks of medicine may undermine patients' confidence in a successful outcome from treatment ${ }^{30}$; legal opinion favours full discussions. ${ }^{31}$

Doctors require more training in how to communicate with patients about medical benefit and risk. This training should inculcate awareness of the individual patient's grasp of the essential features of his or her own illness and its treatment. In addition, training in decision analysis can help doctors in the difficult job of balancing risks, costs, and benefits. ${ }^{32}$ If adverse reactions occur, doctors need to understand that a timely and straightforward explanation can often prevent a hostile and unrewarding confrontation.

If we accept that adverse drug reactions account for an important but still uncertain number of consultations $^{6710-12}$ and that a significant proportion of this is due to prescribers' errors or negligence, then the

\section{Box 2-Content of patient information leaflet required under EC directive 92/27}

(a) The brand name, followed by the generic title and the pharmaceutical form and/or strength

A full quantitative declaration of active ingredients along with a qualitative listing of certain excipients (inactive ingredients)

The pharmaceutical form and a determination of The contents by weight, volume, or number of dosage units

The therapeutic group in terms easily comprehensible to the patient

The name and address of the marketing authorisation holder

The name and address of the manufacturer

(b) The therapeutic indication(s)

(c) Information necessary before taking the product: Contra-indications Precautions for use

Drug interactions and other forms of interaction Any special warnings-for example, pregnancy or breast feeding

(d) Instructions for use

(e) Description of adverse effects

(f) Expiry date and special storage instructions

(g) Date of most recent revision of leaflet 


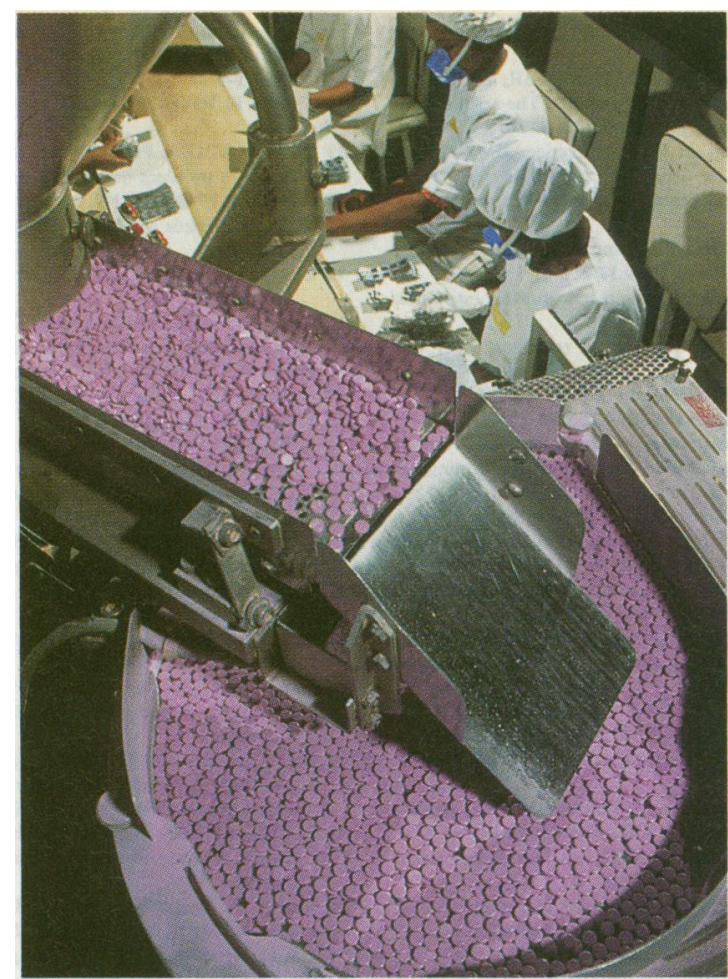

Errors in manufacturing of drugs are fortunately rare; errors by doctors are much more common

obvious way to achieve the safer use of medicines is to improve teaching of therapeutics. Education in therapeutics is far from adequate. Even in the most avant garde curriculums such as those of the University of Limburg in the Netherlands only $5 \%$ of teaching time is devoted to therapeutics, ${ }^{33}$ and undergraduate curriculums in the United Kingdom probably do not fare much better. Eighty years ago there were fewer than 10 specific treatments (mercury for syphilis, quinine for malaria, and emetine for amoebic dystentery, for example); this has now grown to over 2500 drugs. Both undergraduate and continuing education in therapeutics should be high on the agenda if we are to achieve safer use of medicines. An altogether different (but as yet untried) approach to improving the safety of prescribing was advocated by Vincent et al-selecting only the entrants to medical schools who are least prone to making errors.

\section{Role of pharmacists}

Medicines available only on prescription are increasingly being transferred to pharmacy products which patients buy themselves. The increase in prescription charge to $£ 5.25$ per item means that many simple remedies are now available more cheaply over the counter. ${ }^{35}$ These trends have placed more of the onus for advising patients on the shoulders of community pharmacists. Counselling patients is a service for which community pharmacists are paid as part of their dispensing fees. ${ }^{36}$ The conflicting evidence about the advice that is being provided in community pharmacies $^{37-39}$ needs clarification, and pharmacists need more training in how best to communicate information on medicines. ${ }^{40}$ The recent establishment of a chair in community pharmacy at the School of Pharmacy is a welcome step.

Moves enhancing the health care role of the pharmacist may relieve pressure on general practitioners and so allow them longer consultation times. On the other hand, general practitioners now need to have more knowledge of over the counter products and indeed of traditional medicines, ${ }^{41}$ which are becoming increasingly popular.

\section{Role of government}

As is well known, the Licensing Authority ensures the quality, safety, and efficacy of medicines used in the United Kingdom, and the NHS research and development programme will contribute significantly to the evaluation of new health care technologies. ${ }^{42}$ The rapid spread of computer technology throughout general practices in Britain should now be harnessed to further enhance the safety of medicines and of the practice of medicine. A start has already been made as the former VAMP database ${ }^{4344}$ is now owned by the Department of Health. In addition, the Department of Health and the Scottish Home and Health Department have given support to the medicines monitoring unit in Tayside $^{45}$ and the general practice administration system for Scotland. The development of these initiatives has been constrained by funding. Joint funding from industry and government could greatly improve evaluation of drug safety signals now that technology is sufficiently developed. There is a need for visionary strategic management of our valuable databases.

\section{Role of the media}

Perceptions of risk will be inaccurate if the information provided is itself inaccurate or distorted. This applies as much to information provided by the media as it does to the package inserts accompanying medicines. The way the media commonly handle information about drugs has been described by Brown: "Stories involving ADRs and their victims are generally classified as being stories about quackery...the starting point for the journalist investigating an ADR story is that innocent people have been harmed when they thought they were being helped; that the provider of the treatment must have been either less than honest in his claims or negligent in the way that he conducted his experiments; and that doctors and authorities were duped or bribed. His task is to prove that any or all of these assumptions are true."

A recent editorial in a British newspaper said, "There is nothing quite so irresponsible as the media in hot pursuit of a health scare and nothing quite so gullible as the public presented with one." 47 This editorial referred to the recent public concern over necrotising fasciitis. It highlighted not only the poverty of public understanding of health risks but also the inadequacy of some of the experts' responses to legitimate public concerns. By giving the risk of dying from this condition in the United Kingdom as approximately equivalent to the risk of dying by being struck by lightning, the writer aligned himself with other responsible journalists seeking to inform rather than to alarm (L Payer; R Myers, First international symposium of Medical Benefit/Risk Foundation, Frankfurt, 1994) There is clearly a need for a dialogue between those who communicate directly with the public about medical treatments and those professionally involved in appraising the benefits and risks of medicines.

We thank Dr D Fitzgerald for his valuable contributions to this article.

Funding: None.

Conflict of interest: None.

1 Grimley Evans J, Goldacre MJ, Hodkinson HM, Lamb S, Savory M. Health and function in the Third Age. London: Nuffield Provincial Hospitals Trust, and finc.

2 Cartwright A. Older people, their medicines and their doctors. London: Routledge, 1988

3 Royal Society. Risk analysis perception and management. London: Royal Society, 1982 .

4 Jick H. ADRs the magnitude of the problem. 7 Clin Immunol 1984;74:555-7.

5 Rawlins MD, Jefferys DB. Study of United Kingdom product licence applications containing new active substances. $B M f 1991 ; 302: 322-5$.

6 Hurwitz $\mathrm{N}$, Wade OL. Intensive monitoring of adverse reactions to drugs. BMF 1969;:531-3.

7 Ogilvie RI, Reudy J. Adverse drug reactions during hospitalisation. Can Med Assoc ₹ 1967;97:1450-5.

8 Jick H. Drugs-remarkably non-toxic. N Engl f Med 1974;291:824. 
9 Lawson DH, Hutcheon AW, Jick $H$. Life threatening drug reactions amongs medical inpatients. Scot Med f 1978;24:127.

10 Leape LL, Brennan TA, Laird N, Lawthers AG, Localio AR, Barnes BA et al. The nature of adverse events in hospitalised patients. The results of the Harvard medical practice study II. N Engl f Med 1991;324:377-84.

11 Martys CR. Adverse reactions to drugs in general practice. BMf 1979;ii: 1194-7.

12 Mulroy R. Iatrogenic disease in general practice: its incidence and effects. BMF 1973;ii:407-10.

13 Burkholder DF. Adverse drug effects and their impact on patient care: review of the problem. Drug Intel Clin Pharm 1979;13:421-4.

14 Miller RR. Hospital admissions due to adverse drug reactions. Arch Intern Med 1974;43:219-23.

15 Rawlins MD. Spontaneous reporting of adverse drug reactions. $\mathrm{Br} f \mathrm{Cli}$ Pharmacol 1988;26:1-5, 7-1

16 Abramson NS, Walk KS, Grevik AA, Robinson D, Snyder JV. Adverse occurrences in intensive care units. FAMA 1980;244:1582-4.

17 Ferner RE, Whittington RM. Coroners' cases of death due to errors in prescribing or giving medicines or to adverse drug reactions, Birmingham 1986-1991. I R Soc Med 1994;87:145-8.

18 The NHS: What's the verdict? Which? Way to Health 1995 June:80-3.

19 Ridout S, Waters WE, George CF. Knowledge of attitudes to medicines in the Southampton community. Br f Clin Pharm 1986;21:701-12.

20 George CF, Waters WE, Nicholas JA. Prescription information leaflets: a pilot study in general practice. $B M \Im$ 1983;287:1193-6.

21 Gibbs S, Waters WE, George CF. The design of prescription information leaflets and feasibility of their use in general practice. Pharmaceutical Medicine 1987;2:23-33.

22 Slovic P, Fischhoff B, Lichtenstein S. Perceived risk: psychological factors and social implications. Proc $R$ Soc London $[A]$ 1981;376:17-34.

23 Slovic $\mathrm{P}$. The perception and management of therapeutic risk. Carshalton: Centre for Medicines Research, 1989

24 O'Brien BJ, Ellswood J, Calin A. Perception of prescription durg risks: survey of patients with ankylosing spondylitis. $₹$ Rheumatol 1990;17:503-7.

25 Rawlins MD. Trading risk for benefit. In: Mann RD, ed. Risk and consent to risk in medicine. Carnforth: Parthenon, 1989;193-202.

26 O'Brien BJ, Ellswood J, Calin A. Willingness to accept risk in the treatment of rheumatic disease. F Epidemiol Community Health 1990;44:249-52.

27 Ferner RE. Hazards, risks and reality. Br f Clin Pharmacol 1992;33:125-8.

28 Knight $R$. The importance of list size and consultation length as factors in general practice. $₹ R$ Coll Gen Pract 1987;37:19-22.

29 Bradley CP. Uncomfortable prescribing decisions: a critical incidence study. BMf 1992;304:294-6.

30 Drury VVM. The doctor. In: Inman WHW, ed. The doctor in monitoring for drug safety. 2nd ed. Lancaster: MTP Press, 1986:651-8.
31 Dodds-Smith I. Talking about drug treatments: who should say what to whom? Proceedings of second symposium. London: Consumers' Association, 1995:1-5.

32 Kenney R, Raiffa H. Decisions with multiple objectives. New York: John Wiley, 1976

33 De Vries TPGM. Presenting clinical pharmacology and therapeutics: evaluation of a problem based approach for choosing drug treatments. $\mathrm{Br} f \mathrm{Clin}$ Pharmac 1993;35:591-7.

34 Vincent C, Ennis M, Audley RJ. Medical accidents. Oxford: Oxford University Press, 1993.

35 Consumers' Association. Cheaper than a prescription. London: Consumers' Association, 1993.

36 Royal Pharmaceutical Society of Great Britain. Pharmaceutical care: the future for community pharmacy. London: RPSGB, 1992.

37 Hayes A, Livingstone C. Advice on prescribed medicines in community pharmacies. Pharm f 1990;245:R36.

38 Roberts K. Attitudinal survey in community pharmacy. Br f Pharm Pract 1986;8:387-95.

39 Consumer expectations of community pharmaceutical services-a joint study for the Department of Health. Birmingham: Aston University and MEL Research, 1991.

40 Livingstone C, Hayes A, Ladenheim D. Verbal advice about prescription medicines in community pharmacies. Pharm $\mathcal{f}$ 1993;251:R6.

41 Wilkie A, Cordess C. Ginseng-a root just like a carrot? J R Soc Med 1994;87:594-5.

42 Peckham MI. Research and development for the National Health Service. Lancet 1991;338:367-71.

43 Jick H, Jick SS, Derby LE. Validation of information recorded on genera practitioner based computerised data resource in the UK. BMF 1991;302 766-8.

44 Jick H, Terris BZ, Derby LE, Jick SS. Further validation of information recorded on general practitioner based computerised data resource in UK Pharmacoepidemiology and Drug Safety 1992;1:347-9.

45 MacDonald TM, McDevitt D. The Tayside Medicines Monitoring Unit. In Strom BI, ed. Pharmacoepidemiology 2nd ed. Chichester: Wiley, 1994: 245-55.

46 Brown PJ. Reporting adverse drug reactions: the media approach. In Horisberger B, Dinkel R, eds. The perception and management of drug safety risks. Heidelberg: Springer-Verlag: 149-57.

47 Folly, facts and the killer bug [editorial]. Observer 1994 May 29:26.

48 Coni N, Davison W, Webster S, eds. Lecture notes on geriatrics. Oxford: Blackwell Scientific, 1988

(Accepted 26 fune 1995)

\section{Department of Health's requirement for mandatory collection of data on ethnic group of inpatients}

\section{Peter J Aspinall}

On 1 April the Department of Health introduced the mandatory collection of data on the ethnic group of patients admitted to hospital. Its coding was based on a national minimum standard for classifying ethnic groups, ostensibly using the categories in the 1991 census. In the census, however, one in four people from ethnic groups other than white, including many of mixed parentage, provided non-standard responses to the question on ethnic group. The Department of Health's standard does not include provision for respondents to write in a description of their ethnic group, and this has produced a flawed system out of step with current practice on collection of data on ethnic group. Different methods of analysis preclude comparison with census statistics, and the difficulties in aggregating more detailed local categories to the standard raise concerns about consistency of reporting and quality of the data.

The debate about the collection of ethnic group statistics by census and health agencies in the United Kingdom and North America has been wide ranging and comprehensive. ${ }^{12}$ In particular, attention has been drawn to the necessary interdependence of census and public health surveillance systems and the importance of including free text fields for members of ethnic groups, particularly the growing numbers of people of "mixed parentage" (with parents from different groups), who do not feel catered for by specified categories. $^{3}$ It is therefore surprising and unsatisfactory that the Department of Health's recently introduced mandatory requirement for recording the ethnic group of inpatients does not accord with this emerging consensus.

After the Department of Health attempted unsuccessfully to introduce the collection of statistics on ethnic group through general practice in $1992,{ }^{4}$ the onus for such collection was shifted to secondary care and an implementation date was set for April 1993, coinciding with the general release of statistics on ethnic group from the 1991 census. However, the department did not write to health organisations about its implementation proposals until October 1993..$^{\circ}$ This consultation delayed until 1 April 1995 the start of the collection and recording of data by provider units, as a mandatory part of the contract minimum dataset, on the ethnic group of all hospital inpatients and day cases. $^{?}$

As indicated in the October 1993 circular, national uniformity for coding and classification of ethnic group is required, the notifications making clear that "the ethnic group categories used in the 1991 OPCS census will form the national minimum standard." supporting arguments is that "these categories have already been tested as to public acceptability."

The specimen form for collection of data on ethnic group is similar to, but not identical with, the question in the 1991 census. For example, ethnic group is defined on the form as "how you see yourself, and is a mixture of culture, religion, skin colour, language, the origins of yourself or your family. It is not the same as nationality." In the census it was not defined, the belief being that respondents would answer according to their own perceptions of ethnic group. As in the census, patients are presented with a list of ethnic 